\title{
Immobilization of heavy metals in sewage sludge by using subcritical water technology
}

\author{
Wansheng Shi ${ }^{\mathrm{a}, \mathrm{b}}$, Chunguang Liu ${ }^{\mathrm{a}}$, Dahu Ding ${ }^{\mathrm{a}}$, Zhongfang Lei ${ }^{\mathrm{a}}$, Yingnan Yang ${ }^{\mathrm{a}}$, \\ Chuanping Feng ${ }^{\mathrm{b}}$, Zhenya Zhang ${ }^{\mathrm{a} *}$ \\ ${ }^{a}$ Graduate School of Life and Environmental Sciences, University of Tsukuba, Tsukuba \\ 305-8572, Japan \\ ${ }^{\mathrm{b}}$ School of Water Resources and Environment, China University of Geosciences, Beijing \\ 100083, China
}

*Corresponding author: Zhenya Zhang. Tel/fax.: +81 298534712.

E-mail address: zhang.zhenya.fu@u.tsukuba.ac.jp (Z. Zhang). 


\begin{abstract}
Heavy metals (HMs) immobilization in sewage sludge was investigated by using subcritical water technology (SCWT) in this study. The characteristics of sludge and toxicity of HMs were analyzed after SCWT process. The results showed that besides large reduction in sludge volume, SCWT had some positive effect on HMs dissolution into liquid phase, while the majority of HMs was still accumulated in solid phase. The direct toxicity and bioavailability of HMs in sludge was greatly decreased with no toxicity fractions of HMs highly increased. Pb was always at low risk level and the risk of other HMs was greatly reduced from low risk to no risk after SCWT treatment. Moreover, the leaching toxicity of HMs declined after SCWT and the best result was obtained at $280^{\circ} \mathrm{C}$ with the metal concentrations in leachate decreased by $97.46 \%, 93.91 \%, 86.14 \%$, 73.67\%, 71.93\% and 10.71\% for Cu, Cd, Zn, Cr, Ni and Pb, respectively.
\end{abstract}

Keywords: Sewage sludge; subcritical water technology; heavy metals; immobilization 


\section{Introduction}

Land use is one of the most economic ways for sewage sludge disposal because the sludge can provide many easily available nutrient sources like N, P, K and organic matters. However, accumulated heavy metals (HMs) and their bioavailability are often the limiting factors (Fuentes et al., 2004; Wang et al., 2005). In order to reduce the toxicity of HMs to the environment, two main approaches can be applied, i.e. HMs removal from the sludge or HMs immobilization in the sludge.

After being removed from sludge the total concentrations of HMs can be reduced, resulting in the decrease of potential environmental contamination. This approach includes various extraction methods such as chemical extraction by organic or inorganic acid (Deng et al., 2009), ionic liquids extraction (Fuerhacker et al., 2012), and solidliquid- solid extraction (Sprynskyy, 2009), bioleaching (Liu et al., 2012) and electrokinetic remediation (Hanay et al., 2009), etc. However, these methods are not practical and cost-effective due to their requirement of long contact time and difficulties in removal efficiency control.

HMs immobilization has been widely utilized in soil remediation because of its simplicity and cost-effective management. Some commonly used materials for HMs immobilization are biochar, phosphate, carbonate, silicate and phosphate-, carbonate-, silicate- based minerals (McGowen et al., 2001; Mendez et al., 2012). The immobilization mechanisms are different for specific heavy metals, including precipitation with complex anions, surface adsorption, ion exchange, etc (Basta et al., 2001; Theodoratos et al., 2002). After this process the total HMs concentration in sludge cannot be reduced and its potential environmental contamination sometimes increases. However, the direct toxicity or leachable fractions of some HMs may be reduced, which is much more important for the decrease of environmental risk. For the immobilization of HMs, such methods as forming ceramsite by incineration (Xu et al., 2009), mixing with biochar produced from agricultural residues (Uchimiya et al., 2011; Debela et al., 2012), natural mineral adsorption (Kosobucki et al., 2008), and thermal treatment (Obrador et al., 2001) have been tried and tested. 
Thermal treatment, especially sub- and super- critical water technology is regarded as environmentally friendly and has been used for sewage sludge treatment. It was reported that the toxicity and leaching characteristics of HMs could be greatly changed after thermal treatment at $300-400^{\circ} \mathrm{C}$ ( $\mathrm{Li}$ et al., 2012; Yuan et al., 2011). Up to now, the related research works were conducted at temperatures higher than $300^{\circ} \mathrm{C}$ resulting in higher energy consumption and lower organic matter content left in the sludge. In the present study, subcritical water technology (SCWT) was applied under lower temperatures, and the objective of this study was to: (1) characterize the variation of sludge after SCWT process; (2) analyze the $\mathrm{HMs}(\mathrm{Cr}, \mathrm{Ni}, \mathrm{Cu}, \mathrm{Zn}, \mathrm{Cd}$ and $\mathrm{Pb}$ ) speciation and fractional transformation; (3) evaluate the toxicity and bioavailability of HMs in sludge; and (4) examine the leachability and leaching toxicity of HMs after SCWT.

\section{Materials and methods}

\subsection{Sewage sludge}

Dewatered anaerobically digested sewage sludge was used in this study and obtained from a wastewater treatment center in Ibaraki prefecture, Japan. The sludge was kept in 4 ${ }^{\circ} \mathrm{C}$ after sampling. Before SCWT treatment, the sludge was diluted by adding deionized water, and mixed with an appropriate volume of HMs mixture including $\mathrm{Cr}$ (VI), Ni (II), $\mathrm{Cu}$ (II), Zn (II), Cd (II) and Pb (II) because of very low levels of HMs contained in the

original sewage sludge according to the designed HMs concentrations. The HMs mixture was prepared by using the standard HMs solutions (1000 mg/L in $0.1 \mathrm{M} \mathrm{HNO}_{3}$, respectively), and then adjusted its $\mathrm{pH}$ value to 7.0 with $2 \mathrm{M} \mathrm{NaOH}$ solution. The sludge was homogeneously agitated for $2 \mathrm{~h}$ and then kept in a glass beaker (enclosed by plastic wrap) in refrigerator at $4^{\circ} \mathrm{C}$. During the following week the sludge was stirred manually for 5 min once every day in order to let the supplemented HMs completely dispersed or distributed into the sludge. Table 1 lists the characteristics of the sludge used in this study.

\subsection{SCWT procedure}

The SCWT experiments were conducted at $170{ }^{\circ} \mathrm{C}$ (SCWT170), $200{ }^{\circ} \mathrm{C}$ (SCWT200) and $280{ }^{\circ} \mathrm{C}$ (SCWT280), respectively for $1.0 \mathrm{~h}$ in an enclosed stainless steel reactor with a volume of $200 \mathrm{ml}$. In order to keep the same condition, the added sludge volume was $100 \mathrm{ml}$. After SCWT process, the sludge sample was cooled to ambient temperature, and 
then the liquid phase was collected after separation by vacuum filtration at constant pressure (0.02 MPa) for 10 min and labeled as liquid sample (LS) 170, LS200 and LS280, respectively. The solid residue (SR) was dried at $60{ }^{\circ} \mathrm{C}$ for $48 \mathrm{~h}$, and ground into particle size smaller than $0.15 \mathrm{~mm}$ which was sufficiently fine to be homogeneously mixed, and then stored in enclosed plastic bags as samples of SR170, SR200 and SR280, respectively.

The solid reside (CSR) samples from control experiment (CK, without subcritical treatment) were obtained by directly using the sewage sludge prepared in section 2.1.

\subsection{Fractionation procedure of $\mathrm{HMs}$}

Speciation and extraction of HMs in SR was conducted by using the sequential extraction procedure proposed by Tessier et al. (1979) with $1.0 \mathrm{~g}$ sample. The five fractions were exchangeable metals (F1), metals bound to carbonate (F2), metals bound to iron and manganese oxides (F3), metals bound to organic and sulfide (F4) and metals in residue (F5). For F1 to F4, after every step, the supernatant was collected by centrifuging at 10,000 rpm for $10 \mathrm{~min}$, and diluted to a fixed volume with $2 \% \mathrm{HNO}_{3}$. The supernatant samples were filtered to remove fine particles and digested with $\mathrm{H}_{2} \mathrm{O}_{2}$ and concentrated $\mathrm{HNO}_{3}$ to remove dissolved organics. The HMs in F5 and the total concentration of HMs in SR was extracted by digestion with acid mixture $\left(\mathrm{V}_{\mathrm{HCl}} / \mathrm{V}_{\mathrm{HNO}} /\right.$ $V_{\mathrm{HF}}=3 / 1 / 1$ ) (Bettinelli et al., 2000) in PTFE beakers and heated on a hot plate. All the samples were kept in $4{ }^{\circ} \mathrm{C}$ before analysis.

\subsection{Treatment efficiency assessment}

\subsubsection{Overall performance of SCWT on sewage sludge}

After SCWT treatment, the following parameters were used to demonstrate the performance of SCWT on sewage sludge including moisture, decomposition rate (Eq. 1), organic matter and total HMs content. Low moisture and high decomposition rate can reduce the sludge volume and weight adding benefits to its ultimate disposal. As for agricultural use, a high organic matter content and low total HMs concentration in sludge is of great importance.

Decomposition rate $(\%)=100 \times\left(\mathrm{W}_{0}-\mathrm{W}\right) / \mathrm{W}_{0}$ where $\mathrm{W}_{0}(\mathrm{mg})$ and $\mathrm{W}(\mathrm{mg})$ are the dry weights of sludge before and after SCWT treatment, respectively. 


\subsubsection{Eco-toxicity and bioavailability}

It is widely recognized that the mobility, eco-toxicity and bioavailability of HMs in sludge depends not only on the total concentration but also on their existing forms (Xian, 1989; Angelova et al., 2004). Based on Tessier's method, the eco-toxicity and bioavailability of HMs can be described as: $(\mathrm{F} 1+\mathrm{F} 2)$ concentration of HMs represents direct toxicity and bioavailability $\left(\mathrm{C}_{\mathrm{bio}}\right),(\mathrm{F} 3+\mathrm{F} 4)$ concentration relates to potential toxicity and bioavailability ( $\mathrm{C}_{\mathrm{Pbio}}$ ), while $\mathrm{HMs}$ in $\mathrm{F} 5$ possess no toxicity $\left(\mathrm{C}_{\mathrm{Nbio}}\right)$ (Vela et al., 1993; Li et al., 2012).

More attention should be paid to the weakly bonded fractions (F1+F2) as they can equilibrate with the aqueous phase and thus become more rapidly bioavailable (Sundaray et al., 2011). According to this consideration, specific quantity evaluation of HMs in sludge can be carried out by using a risk assessment code (RAC) based on the proportion of these two fractions $(\mathrm{F} 1+\mathrm{F} 2)$ to the total amount of each metal extracted from the sludge, namely the risk index (RI) (Huang et al., 2011; Singh et al., 2005). The HMs in sludge can be classified by using RAC as no risk, low risk, medium risk, high risk and very high risk when the RI value ranges $<1,1-10,11-30,31-50$ and $>50$, respectively.

Furthermore, the ratio of (F1+F2)/F5 can be used to describe the potential lability of HMs in sludge (Obrador et al., 2001).

\subsubsection{Leachability}

The leachability of HMs in SR directly relates to their availability and toxicity, and can be evaluated by the standard Toxicity Characteristic Leaching Procedure (TCLP). TCLP simulates landfill conditions by using acetic acid solution $(\mathrm{pH} 2.88$, liquid/solid ratio= 20:1). The leaching tests were carried out in polyethylene tubes and shaken at $200 \mathrm{rpm}$ for $18 \mathrm{~h}$. The supernatant was harvested by centrifugation, and then digested with $\mathrm{H}_{2} \mathrm{O}_{2}$ and concentrated $\mathrm{HNO}_{3}$ for $\mathrm{HMs}$ analysis.

\subsection{Analysis}

The moisture or water content in sludge was analyzed by weight loss when heating at $105{ }^{\circ} \mathrm{C}$ for $48 \mathrm{~h}$. The concentration of each HM was determined by using ICP-MS (ELAN DRC-e, PerkinElmer) after filtration with $0.2 \mu \mathrm{m}$ membrane filter. Phosphorus was 
measured with molybdate ascorbic acid method by a Shimadzu UV1800

spectrophotometer. Ammonia nitrogen was analyzed with Nessler's reagent

spectrophotometry method. The organic matter was determined by burning at $873 \mathrm{~K}$ in a muffle. Before the determination of the content of HMs and phosphorus in LS, the samples of LS should be digested with $\mathrm{H}_{2} \mathrm{O}_{2}$ and concentrated $\mathrm{HNO}_{3}$ to remove the dissolved organics. Each test was conducted in triplicate. The results presented in this study were the mean values \pm standard deviation.

\section{Results and discussion}

\subsection{Physicochemical property changes}

Table 2 shows the changes of some physicochemical properties of sludge before and after SCWT process. It can be seen that the decomposition rate of sludge increased with temperature resulting in the decrease of organic matter from $46.09 \%$ to $21.35 \%$ (SR280) and the increase of total phosphorus in SR from $17.15 \mathrm{~g} \mathrm{~kg}^{-1}$ to $25.40 \mathrm{~g} \mathrm{~kg}^{-1}$ (SR280). The $\mathrm{pH}$ value and ammonia concentration in LS increased with the increase of temperature, possibly brought about by the decomposition of dead microbes. The color of SR was changed from grey to black, attributable to some portions of organics being converted into biochar (Hu et al., 2010). The dehydration performance of sludge after SCWT treatment was obtained by vacuum filtration followed by moisture measurement. The water content in the sludge decreased from $85.47 \%$ to $74.74 \%, 62.37 \%$ and $44.68 \%$ after SWCT treatment at $170{ }^{\circ} \mathrm{C}, 200^{\circ} \mathrm{C}$ and $280^{\circ} \mathrm{C}$, resulting in sludge volume reduction approximately by $42 \%, 61 \%$ and $74 \%$, respectively according to the relationship between sludge volume and water content. The results show that stabilization of sludge could be achieved along with large reduction in sludge volume after SCWT process. Based on the results obtained in this study, the higher temperature SCWT process (such as $280^{\circ} \mathrm{C}$ ) seems to be more preferable in view of the ultimate disposal of sludge. The phenomenon, i.e. sludge stabilization and volume reduction after SCWT treatment may have some contribution to the HMs dissolution and distribution in the treated sludge, which is explored further in the following experiments.

\subsection{HMs dissolution and distribution in SR and LS}


The redistributions of HMs in LS and SR are shown in Figs. 1 and 2, respectively. The result indicates that HMs could be dissolved from solid sludge particles into liquid phase resulting in increased concentrations in liquid phase after the SCWT process. This observation might be brought about by the degradation of extracellular polymeric substances and thereafter some HMs binding to them were released into the liquid phase (Appels et al., 2010). The dissolution of HMs into liquid seems to be coupled with the dissolution of total phosphorus (Table 2), providing a chance for HMs adsorption (Eq. 2), precipitation (Eqs. 3 and 4) and thus immobilization in the sludge (McGowen et al., 2001).

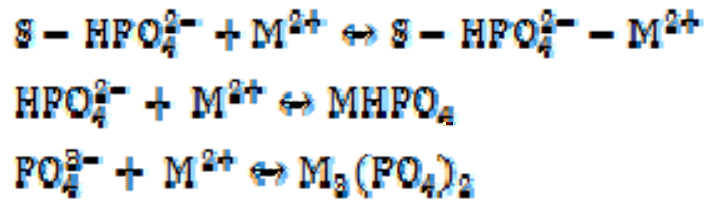

where S represents sludge particle, and $\mathrm{M}$ represents heavy metal.

As for total content, different metals behaved differently. The released amount into liquid increased with the increase of temperature for $\mathrm{Zn}, \mathrm{Cd}$ or $\mathrm{Pb}$, while the highest release was obtained at $200{ }^{\circ} \mathrm{C}$ for $\mathrm{Cr}$, Ni or $\mathrm{Cu}$. Although SCWT process seems to have some positive effect on HMs release from sludge into liquid phase, the amount of HMs in LS was very low ( $<1.3 \%$ of the total) with the majority being remained ( $>98.7 \%)$ in SR. Figure 2 shows that the HMs contents increase in SR with the increase of SCWT temperature, i.e. HMs tend to be accumulated in SR after SCWT treatment. This observation signals an increased environmental risk of sludge with the increase of SCWT treatment temperature if only using the total HMs content as an assessment index. 


\subsection{Fraction of HMs and environmental risk analysis}

\subsubsection{Fraction and fractional transformation of HMs}

By using the Tessier's method, different fractions of the six $\mathrm{HMs}(\mathrm{Cr}, \mathrm{Ni}, \mathrm{Cu}, \mathrm{Zn}$, $\mathrm{Cd}$ and $\mathrm{Pb}$ ) in the sludge were extracted and analyzed before and after SCWT treatment (Fig. 3).

The main existing forms in CSR were found to be different for the six HMs. $64.69 \%$ of $\mathrm{Cu}$ was bound to organic and sulfide substances (F4), which may be attributed to its high stability of complexion with organic matter (Staelens et al., 2000; Fuentes et al., 2008) and sulfide. Pb was found to be mainly existed in F4 (63.90\%), and the majority of $\mathrm{Ni}$, about $60.20 \%$ was in the residual fraction (F5). Zn was found mainly in three forms in the sludge, namely F5 (39.48\%), F4 (31.63\%) and F3 (26.95\%). Two forms, F5 (47.33\%) and F4 (45.07\%) were the main existing ones for $\mathrm{Cr}$ in the sludge. About half of Cd was bound to iron and manganese oxides (F3, 53.51\%). It should be stated that all the six HMs are very low at exchangeable (F1, < $5 \%$ ) and carbonate bounded (F2, <2\%) fractions in CSR (except for Cd in F2, $13.30 \%)$.

Figure 3 also illustrates the effect of SCWT treatment on the redistribution of HMs in SR. The contents of $\mathrm{Cu}$ and $\mathrm{Pb}$ were all sharply decreased in the first 3 fractions while increased in F5 after SCWT, especially for $\mathrm{Cu}$ in F1 and Pb in F2 with the contents decreased negatively with treatment temperature and for $\mathrm{Pb}$ in F5 increased positively with temperature. In addition, SCWT exerted different effect on both $\mathrm{Cu}$ and $\mathrm{Pb}$ in $\mathrm{F} 4$, and the $\mathrm{F} 4$ of $\mathrm{Cu}$ decreased after treatment at $170^{\circ} \mathrm{C}$ and $280^{\circ} \mathrm{C}$ while $\mathrm{Pb}$ content in $\mathrm{F} 4$ was reduced at temperatures higher than $200^{\circ} \mathrm{C}$.

In the case of Zn, the contents decreased in F1 (except in SR170), F2 and F3 while increased in F4 and F5. A considerable reduction of Ni content was observed in F1 (except treatment at $200^{\circ} \mathrm{C}$ ), F2, F3 and F4, and the corresponding content of F5 was significantly increased.

As for Cr and Cd, SCWT showed some positive effect on the reduction of F1 and $\mathrm{F} 2$ fractions in the sludge. After treatment at $170^{\circ} \mathrm{C}$ and $280^{\circ} \mathrm{C}, \mathrm{Cr}$ content was observed to decrease in F4 and increase in F5 (Fig. 3). The percentages of F3 (except for $280^{\circ} \mathrm{C}$ ) and $\mathrm{F} 4$ of Cd in the sludge increased after SCWT treatment, while the F5 fraction firstly increased and then decreased with temperature. Still, the major form of Cd was F4 after treated at $280^{\circ} \mathrm{C}$, mostly contributed by the conversion from its F3 fraction. 
From the above results, it can be concluded that the weakly bounded forms (F1 and F2) of HMs are all decreased in sludge after SCWT treatment except for F1fractions of $\mathrm{Zn}$ and $\mathrm{Ni}$ after treatment at $170^{\circ} \mathrm{C}$ and $200^{\circ} \mathrm{C}$. The $\mathrm{F} 5$ fractions of $\mathrm{HMs}$ are all increased after SCWT with the exception of Zn and Cr in SR200 and Cd in both SR200 and SR280. Most importantly, the proportions of (F1+F2) for the six HMs are at the lowest levels in all the SR280 samples (Fig. 3); and the corresponding first four fractions of HMs are all decreased with F5 increased accordingly after SCWT treatment at $280{ }^{\circ} \mathrm{C}$ (except for Cd). The results indicate that SCWT treatment at 280 ${ }^{\circ} \mathrm{C}$ is the best condition with respect to the toxicity and bioavailablity of HWs (i.e. existing forms).

From above results, it can be inferred that HMs in sludge could be transformed from weakly bounded fractions (especially F1 and F2) to a more stable state (F5) during SCWT process, implying that some complexation might occur between HMs and the crystal lattices of the residual solid phase. The above fractional transformation and redistribution of HMs can possibly realize the immobilization of HMs in sludge, and some anions such as phosphate (Table 2) and silicate contained in the sludge may recombine with these HMs to become stable precipitate with very low solubility (Chen et al., 2007; Geebelen et al., 2006). The detailed mechanisms are still under investigation.

\subsubsection{Eco-toxicity and bioavailability assessment}

Table 3 shows the variation of $\mathrm{C}_{\text {bio }}, \mathrm{C}_{\text {Pbio }}$ and $\mathrm{C}_{\text {Nbio }}$ of HMs in the sludge after SCWT treatment, which can be used to assess the eco-toxicity and bioavailability. The significance of temperature on the fraction distribution of HMs is indicated by F- and p- values obtained by one-way analysis of variance (ANOVA) with the experimental data (Table 3). The statistical results show that treatment temperature significantly influences the concentrations of the three portions of HMs during SCWT process except for $\mathrm{Pb}$ in $\mathrm{C}_{\text {Pbio }}$.

From Table 3 and Fig. 3, the proportions of each metal existed in the first two fractions $(\mathrm{F} 1+\mathrm{F} 2)$ are very low (less than 5\%, except for Cd, 16.67\%) in CSR. The concentrations of the HMs in these two parts (except for Zn in SR170) were all decreased after SCWT treatment, indicating its positive effect on reducing the direct toxicity and bioavailability of these HMs in sludge (Li et al., 2012; Huang et al., 2011). The concentration of Cr in SR200 was the same as that in CSR denoting that 
the direct toxicity of Cr was not reduced after SCWT at $200^{\circ} \mathrm{C}$. The SCWT treatment at $280{ }^{\circ} \mathrm{C}$ exhibited the most significant effect on reducing this toxicity due to the lowest $\mathrm{C}_{\text {bio }}$ of HMs obtained in SR280, and the HMs in the bioavailable fraction was decreased by $53.75 \%, 69.32 \%, 81.15 \%, 64.75 \%$, $98.37 \%$ and $61.18 \%$ for $\mathrm{Cr}, \mathrm{Ni}$, $\mathrm{Cu}, \mathrm{Zn}, \mathrm{Cd}$ and $\mathrm{Pb}$, respectively.

Except that $\mathrm{Ni}$ was mainly existed in the non-toxicity fraction, the other five metals were mainly found in the forms with potential toxicity in CSR (Table 3). After SCWT process, the $\mathrm{C}_{\text {Pbio }}$ values of $\mathrm{Cu}$ and $\mathrm{Cd}$ increased with temperature while $\mathrm{C}_{\text {Pbio }}$ of $\mathrm{Pb}$ remained relatively stable; the $\mathrm{C}_{\mathrm{Pbio}}$ values of $\mathrm{Cr}$ and $\mathrm{Zn}$ slightly decreased at $170{ }^{\circ} \mathrm{C}$ and then increased at higher temperatures. Although having an increase trend, the $\mathrm{C}_{\text {Pbio }}$ values of $\mathrm{Ni}$ in SR were less than those in CSR. And the potential toxicity of Cr, $\mathrm{Cu}, \mathrm{Zn}$ and Cd in sludge was increased after SCWT treatment at temperatures higher than $200^{\circ} \mathrm{C}$. This increase was more significant for $\mathrm{Cd}$ as its concentration even doubled in SR280. The potential toxicity of $\mathrm{Ni}$ was reduced while that of $\mathrm{Pb}$ kept almost unchanged. Restated, the total concentrations of $\mathrm{Ni}$ and $\mathrm{Pb}$ increased after SCWT (Fig. 2), but the proportion of these two metals relating to potential toxicity was sharply decreased (corresponding to large increase in F3+F4, Fig. 3). This observation indicates that the SCWT process seems to have more significant effect on reducing toxicity and enhancing immobilization of $\mathrm{Pb}$ and $\mathrm{Ni}$ in the sludge.

All the $\mathrm{C}_{\text {Nbio }}$ concentrations of HMs increased (except Cd in SR200) after SCWT treatment (Table 3), which would be more meaningful for HWs immobilization if the proportions of these metals in no toxicity state also increased. From Fig.3, Pb and $\mathrm{Ni}$ associated with no toxicity were both increased with temperature, and other HMs in this fraction were increased after being treated at $170{ }^{\circ} \mathrm{C}$ and $280^{\circ} \mathrm{C}$. Besides, the percentage increase in fraction F5 together with the decrease in the easily available fractions (F1 + F2) (Fig. 3), thus a lower ratio of (F1+F2)/F5, implies a reduced potential lability of HMs in sludge after the SCWT treatment (Obrador et al., 2001). Taken the reduction effect on the direct toxicity of HWs into consideration, the SCWT process under $280^{\circ} \mathrm{C}$ is proposed for the best HMs immobilization in sewage sludge in this study.

\subsubsection{RAC analysis}

The environmental risk of these HMs in CSR and SR can also be evaluated by RAC using $(\mathrm{F} 1+\mathrm{F} 2)$ ratios because these weakly bonded fractions are easily affected by 
ionic strength and vulnerable to $\mathrm{pH}$ changes in soil environment resulting in a very high mobility (Lasheen and Ammar, 2009; Yuan et al., 2011). Based on the results of Fig. 3, all the metals showed low risk in CSR, and the risk of the six HMs was greatly lowered after SCWT, especially for $\mathrm{Cu}, \mathrm{Zn}, \mathrm{Ni}$ and $\mathrm{Cd}$ with their risk changed from low risk to no risk. The easily bioavailable HMs (F1 and F2) were mainly transformed into the relatively stable heavy metal fractions (F3, F4 and F5) after SCWT process, resulting in the decrease of direct toxicity and environmental risk of HMs. In addition, no environment risk of HMs in SR was attained after being treated at $280{ }^{\circ} \mathrm{C}$ except for $\mathrm{Pb}$. Still, the risk of $\mathrm{Pb}$ remained at a very low level $(\mathrm{RI}=$ ? $<1-10)$.

\subsection{Leaching test and leaching toxicity}

The leaching toxicity of HMs in CSR and SR was determined with the standard TCLP test shown in Table 4 and Fig. 4.

The metal concentrations in the leachate extracted from CSR were 0.30, 11.75, 5.05, 2.25, 0.72 and $0.03 \mathrm{mg} \mathrm{kg}^{-1}$ for $\mathrm{Cr}, \mathrm{Ni}, \mathrm{Cu}, \mathrm{Zn}, \mathrm{Cd}$ and $\mathrm{Pb}$, respectively. The concentrations of leachable HMs were lower than the USEPA permissible limits (SW846) expect for that of $\mathrm{Ni}$ in CSR which exceeded the limit value by about two times. The concentrations of leached $\mathrm{Cu}$, Zn and Cd from sludge were declined after SCWT process, while $\mathrm{Cr}$ and $\mathrm{Ni}$ behaved slightly different. The concentration of $\mathrm{Cr}$ and $\mathrm{Ni}$ in leachate from SR170 and SR280 decreased but increased from SR200. In the case of $\mathrm{Pb}$, although the leachable contents increased in SR170 and SR200, the concentrations were very low (0.045 and $0.081 \mathrm{mg} \mathrm{kg}^{-1}$, respectively) showing no risk, and the leachable content was decreased in SR280. Briefly, all the lowest concentrations of leachable HMs were found in SR280, and the concentrations decreased by $97.46 \%$, 93.91\%, 86.14\%, 73.67\%, 71.93\% and 10.71\% for $\mathrm{Cu}, \mathrm{Cd}, \mathrm{Zn}, \mathrm{Cr}, \mathrm{Ni}$ and $\mathrm{Pb}$, respectively, indicating the release of HMs (except for $\mathrm{Pb}$ ) was significantly decreased. The SCWT process at $280{ }^{\circ} \mathrm{C}$ exhibited the most significant effect on reducing the leaching risk of HMs to the environment.

The leaching rates of the six HMs are shown in Fig. 4. This indicator is defined as the ratio of individual metal concentration in the leachate to the total concentration of this metal (Huang et al., 2011), which can be used to reflect the proportion of HMs in the leachable state. The decreased leaching rates of $\mathrm{Ni}, \mathrm{Cu}, \mathrm{Zn}$ and $\mathrm{Cd}$ indicate the decrease in the leachable fraction of these metals, which is in contrast to the leachability increase of Cr from SR200 and Pb from SR170 and SR200. From Fig. 4 
and Table 4, it's obvious that the HMs related to leachable fraction were at the lowest proportions in the sludge after SCWT treatment at $280{ }^{\circ} \mathrm{C}$, clearly showing the reduced leaching toxicity and leachable fraction of HMs in sludge after SCWT process (especially $280^{\circ} \mathrm{C}$ ). This observation coincides with the declination of weakly bounded fractions (F1+F2) shown in Fig 3.

\subsection{Implication of this study to practice}

In this study, the risk of HMs in sludge is mainly assessed both by their total concentrations and existing forms. The experimental data shows that the tested HMs can be transformed into more stable existing forms in the sludge after SCWT process, although the total metal concentrations tend to increase due to the large decrease of sludge volume. This phenomenon is also in agreement with the decreased bioavailability and leachability tests of the treated sludge. Restated, the total concentrations of HMs remained in the solid phase are still lower than the USEPA permissible limits (SW-846). The results up to present suggest that SCWT could be a promising sludge treatment method for HMs immobilization, after which the treated sludge can be more appropriate for agricultural application due to much less or no risk of HMs to the environment. Our followed-up research will focus on the mechanisms involved in this process and the enhancement effect of some additives on HMs immobilization in the sludge.

\section{Conclusions}

The present study indicates that SCWT is a promising method for sewage sludge disposal. After SCWT treatment, organics stabilization and volumetric reduction of sludge can be achieved. Although the majority of HMs is still accumulated in the solid phase, most of the HMs can be transformed from easily available fractions to relatively stable states resulting in large decrease in direct toxicity and environmental risk of the treated sludge. Moreover, the leachable fraction and the leaching toxicity of HMs are also largely decreased after SCWT. Among the tested conditions, SCWT at $280^{\circ} \mathrm{C}$ is preferable for the final disposal of sludge.

\section{References}


1. Angelova, V., Ivanov, K., Ivanova, R., 2004. Effect of chemical forms of lead, cadmium, and zinc in polluted soils on their uptake by tobacco. J. Plant Nutr. 27, 757-773.

2. Appels, L., Degreve, J., Van der Bruggen, B., Van Impe, J., Dewil, R., 2010. Influence of low temperature thermal pre-treatment on sludge solubilisation, heavy metal release and anaerobic digestion. Bioresour. Technol.101, 5743-5748.

3. Basta, N. T., Gradwohl, R., Snethen, K. L., Schroder, J. L., 2001. Chemical immobilization of lead, zinc, and cadmium in smelter-contaminated soils using biosolids and rock phosphate. J. Environ. Qual. 30, 1222-1230.

4. Bettinelli, M., Beone, G. M., Spezia, S., Baffi, C., 2000. Determination of heavy metals in soils and sediments by microwave-assisted digestion and inductively coupled plasma optical emission spectrometry analysis. Anal. Chim. Acta 424, 289-296.

5. Chen, S., Xu, M., Ma, Y., Yang, J., 2007. Evaluation of different phosphate amendments on availability of metals in contaminated soil. Ecotoxicol. Environ. Saf. 67, 278-285.

6. Debela, F., Thring, R. W., Arocena, J. M., 2012. Immobilization of Heavy Metals by Co-pyrolysis of Contaminated Soil with Woody Biomass. Water Air Soil Pollut. 223, 1161-1170.

7. Deng, J., Feng, X., Qiu, X., 2009. Extraction of heavy metal from sewage sludge using ultrasound-assisted nitric acid. Chem. Eng. J. 152, 177-182.

8. Fuentes, A., Llorens, M., Saez, J., Soler, A., Aguilar, M. I., Ortuno, J. F., Meseguer, V. F., 2004. Simple and sequntial extractions of heavy metals from different sewage sludges. Chemosphere 54, 1039-1047.

9. Fuentes, A., Llorens, M., Saez, J., Aguilar, M. I., Ortuno, J. F., Meseguer, V. F., 2008. Comparative study of six different sludges by sequential speciation of heavy metals. Bioresour. Technol. 99, 517-525.

10. Fuerhacker, M., Haile, T. M., Kogelnig, D., Stojanovic, A., Keppler, B., 2012. Application of ionic liquids for the removal of heavy metals from wastewater and activated sludge. Water Sci. Technol. 65, 1765-1773.

11. Geebelen, W., Sappin-Didier, V., Ruttens, A., Carleer, R., Yperman, J., BongueBoma, K., Mench, M., Van der Lelie, N., Vangronsveld, J., 2006. Evaluation of cyclonic ash, commercial Na-silicates, lime and phosphoric acid for metal 
12. Hanay, O., Hasar, H., Kocer, N. N., 2009. Effect of EDTA as washing solution on removing of heavy metals from sewage sludge by electrokinetic. J. Hazard. Mater. 169, 703-710.

13. Hu, B., Wang, K., Wu, L., Yu, S., Antonietti, M., Titirici, M. M., 2010.

Engineering Carbon Materials from the Hydrothermal Carbonization Process of Biomass. Adv. Mater. 22, 813-828.

14. Huang, H., Yuan, X., Zeng, G., Zhu, H., Li, H., Liu, Z., Jiang, H., Leng, L., Bi, W., 2011. Quantitative evaluation of heavy metals' pollution hazards in liquefaction residues of sewage sludge. Bioresour. Technol. 102, 10346-10351.

15. Kosobucki, P., Kruk, M., Buszewski, B., 2008. Immobilization of selected heavy metals in sewage sludge by natural zeolites. Bioresour. Technol. 99, 5972-5976.

16. Lasheen, M. R., Ammar, N. S., 2009. Assessment of metals speciation in sewage sludge and stabilized sludge from different Wastewater Treatment Plants, Greater Cairo, Egypt. J. Hazard. Mater. 164, 740-749.

17. Li, L., Xu, Z., Zhang, C., Bao, J., Dai, X., 2012. Quantitative evaluation of heavy metals in solid residues from sub- and super-critical water gasification of sewage sludge. Bioresour. Technol. 121, 169-175.

18. Liu, F., Zhou, L., Zhou, J., Song, X., Wang, D., 2012. Improvement of sludge dewaterability and removal of sludge-borne metals by bioleaching at optimum $\mathrm{pH}$. J. Hazard. Mater. 221, 170-177.

19. McGowen, S. L., Basta, N. T., Brown, G. O., 2001. Use of diammonium phosphate to reduce heavy metal solubility and transport in smelter-contaminated soil. J. Environ. Qual. 30, 493-500.

20. Mendez, A., Gomez, A., Paz-Ferreiro, J., Gasco, G., 2012. Effects of sewage sludge biochar on plant metal availability after application to a Mediterranean soil. Chemosphere 89, 1354-1359.

21. Obrador, A., Rico, M. I., Alvarez, J. M., Novillo, J., 2001. Influence of thermal treatment on sequential extraction and leaching behaviour of trace metals in a contaminated sewage sludge. Bioresour. Technol. 76, 259-264.

22. Singh, K. P., Mohan, D., Singh, V. K., Malik, A., 2005. Studies on distribution and fractionation of heavy metals in Gomti river sediments - a tributary of the Ganges, India. J. Hydrol. 312, 14-27. 
23. Sprynskyy, M., 2009. Solid-liquid-solid extraction of heavy metals (Cr, Cu, Cd, $\mathrm{Ni}$ and $\mathrm{Pb}$ ) in aqueous systems of zeolite-sewage sludge. J. Hazard. Mater. 161, 1377-1383.

24. Staelens, N., Parkpian, P., Polprasert, C., 2000. Assessment of metal speciation evolution in sewage sludge dewatered in vertical flow reed beds using a sequential extraction scheme. Chem. Speciation and Bioavailability 12, 97-107.

25. Sundaray, S. K., Nayak, B. B., Lin, S., Bhatta, D., 2011. Geochemical speciation and risk assessment of heavy metals in the river estuarine sediments-A case study: Mahanadi basin, India. J. Hazard. Mater. 186, 1837-1846.

26. Tessier, A., Campbell, P. G. C., Bisson, M., 1979. Sequential Extraction Procedure for The Speciation of Particulate Trace-Metals. Anal. Chem. 51, 844-851.

27. Theodoratos, P., Papassiopi, N., Xenidis, A., 2002. Evaluation of monobasic calcium phosphate for the immobilization of heavy metals in contaminated soils from Lavrion. J. Hazard. Mater. 94, 135-146.

28. Uchimiya, M., Wartelle, L. H., Klasson, K. T., Fortier, C. A., Lima, I. M., 2011. Influence of Pyrolysis Temperature on Biochar Property and Function as a Heavy Metal Sorbent in Soil. J. Agric. Food Chem. 59, 2501-2510.

29. Vela, L. D., Jervis, R. E. , Krishnan, S. S., 1993. The leachability of elements in solid- wastes. J.Radioanal. Nucl. Chem. Art. 169, 39-45.

30. Wang, C., Hu, X., Chen, M., Wu, Y., 2005. Total concentrations and fractions of $\mathrm{Cd}, \mathrm{Cr}, \mathrm{Pb}, \mathrm{Cu}, \mathrm{Ni}$ and $\mathrm{Zn}$ in sewage sludge from municipal and industrial wastewater treatment plants. J. Hazard. Mater. 119, 245-249.

31. Xian, X., 1989. Effect of Chemical Forms of Cadmium, Zinc, and Lead in Polluted Soils on Their Uptake by Cabbage Plants. Plant Soil 113, 257-264.

32. Xu, G., Zou, J., Li, G., 2009. Stabilization/Solidification of Heavy Metals in Sludge Ceramsite and Leachability Affected by Oxide Substances. Environ. Sci. Technol. 43, 5902-5907.

33. Yuan, X., Huang, H., Zeng, G., Li, H., Wang, J, Zhou, C., Zhu, H., Pei, X., Liu, Z., Liu, Z., 2011. Total concentrations and chemical speciation of heavy metals in liquefaction residues of sewage sludge. Bioresour. Technol. 102, 4104-4110. 
Table 1. Physicochemical characteristics of the sewage sludge.

\begin{tabular}{lr}
\hline Parameters & \multicolumn{1}{c}{ Value $^{\text {a }}$} \\
\hline Solid content (\%) & $14.53 \pm 0.39$ \\
Organic matter (\%) & $46.09 \pm 0.16$ \\
Total phosphorus ( $\mathrm{g} \mathrm{kg}^{-1}$ dry weight) & $17.15 \pm 1.84$ \\
$\mathrm{pH}$ & $6.43 \pm 0.21$ \\
$\mathrm{HMs}$ (mg kg-1 dry weight) & \\
$\mathrm{Cr}$ & $150.18 \pm 1.22$ \\
$\mathrm{Ni}$ & $638.56 \pm 96.15$ \\
$\mathrm{Cu}$ & $415.00 \pm 29.46$ \\
$\mathrm{Zn}$ & $750.65 \pm 59.59$ \\
$\mathrm{Cd}$ & $73.02 \pm 0.63$ \\
$\mathrm{~Pb}$ & $122.14 \pm 9.06$ \\
\hline
\end{tabular}

${ }^{\mathrm{a}}$ Mean \pm standard deviation. 
Table 2. Physicochemical property changes of sewage sludge before and after SCWT treatment.

\begin{tabular}{|c|c|c|c|c|}
\hline & $\mathrm{CK}^{\mathrm{a}}$ & SCWT170 ${ }^{\mathrm{b}}$ & SCWT200 ${ }^{\mathrm{b}}$ & SCWT280 ${ }^{\mathrm{b}}$ \\
\hline Decomposition rate (\%) & 0 & $14.32 \pm 0.22$ & $18.99 \pm 0.19$ & $32.47 \pm 0.12$ \\
\hline Moisture (\%) (SR ${ }^{c}$ ) & $85.47 \pm 0.39$ & $74.74 \pm 0.25$ & $62.37 \pm 0.31$ & $44.68 \pm 0.46$ \\
\hline Organic matter (\%) (SR ${ }^{\mathrm{c}}$ ) & $46.09 \pm 0.16$ & $34.98 \pm 0.21$ & $29.27 \pm 0.14$ & $21.35 \pm 0.10$ \\
\hline $\mathrm{pH}\left(\mathrm{LS}^{\mathrm{d}}\right)$ & N.D. & $7.61 \pm 0.18$ & $8.52 \pm 0.13$ & $9.17 \pm 0.07$ \\
\hline $\mathrm{NH}_{4}{ }^{+}-\mathrm{N}\left(\mathrm{LS}, \mathrm{mg} \mathrm{l}^{-1}\right)$ & N.D. & $2357.24 \pm 17.91$ & $2586.24 \pm 8.99$ & $3566.17 \pm 7.37$ \\
\hline Total phosphorus (mg l $\left.\mathrm{l}^{-1}\right)\left(\mathrm{LS}^{\mathrm{d}}\right)$ & N.D. & $12.48 \pm 1.04$ & $15.81 \pm 0.83$ & $30.43 \pm 2.17$ \\
\hline Total phosphorus $\left(\mathrm{g} \mathrm{kg}^{-1}\right)\left(\mathrm{SR}^{\mathrm{c}}\right)$ & $17.15 \pm 1.84$ & $20.02 \pm 0.94$ & $21.17 \pm 2.01$ & $25.40 \pm 1.29$ \\
\hline
\end{tabular}

${ }^{a}$ CK-control experiment (without SCWT treatment). ${ }^{b}$ SCWT170, SCWT200, and

SCWT280 are the sludges after SCWT treatment under 170, 200, and $280{ }^{\circ} \mathrm{C}$, respectively. ${ }^{\mathrm{c}}$ SR-solid residue. ${ }^{\mathrm{d}}$ LS-liquid sample after vacuum filtration. ${ }^{\mathrm{e}}$ N.D., No determination because of little liquid (LS) could be obtained from control samples due to the high solids content and high viscosity of sludge used in this study. 
Table 3. Concentrations of HMs in bioavailable $\left(\mathrm{C}_{\text {bio }}\right)$, potential bioavailable $\left(\mathrm{C}_{\mathrm{Pbio}}\right)$ and non-bioavailable $\left(\mathrm{C}_{\mathrm{Nbio}}\right)$ fractions in sludge before and after subcritical water treatment (unit: $\left.\mathrm{mg} \mathrm{kg}^{-1}\right)(\mathrm{n}=3, \alpha<0.05)$.

\begin{tabular}{|c|c|c|c|c|c|c|c|}
\hline & & $\mathrm{Cr}$ & $\mathrm{Ni}$ & $\mathrm{Cu}$ & $\mathrm{Zn}$ & $\mathrm{Cd}$ & $\mathrm{Pb}$ \\
\hline \multirow[t]{7}{*}{$\mathrm{C}_{\text {bio }}$} & $\operatorname{CSR}^{\mathrm{a}}$ & $1.60 \pm 0.35$ & $24.38 \pm 0.82$ & $12.20 \pm 0.26$ & $14.98 \pm 3.10$ & $12.25 \pm 0.44$ & $5.95 \pm 0.92$ \\
\hline & SR170 ${ }^{b}$ & $1.34 \pm 0.18$ & $14.79 \pm 2.36$ & $6.15 \pm 0.75$ & $22.65 \pm 1.91$ & $2.12 \pm 0.37$ & $2.00 \pm 0.05$ \\
\hline & SR200 ${ }^{b}$ & $1.59 \pm 0.24$ & $19.67 \pm 0.55$ & $4.36 \pm 1.18$ & $10.90 \pm 0.51$ & $1.36 \pm 0.02$ & $2.82 \pm 0.88$ \\
\hline & SR280 ${ }^{b}$ & $0.74 \pm 0.11$ & $7.48 \pm 0.65$ & $2.30 \pm 1.27$ & $5.28 \pm 1.19$ & $0.20 \pm 0.01$ & $2.31 \pm 0.34$ \\
\hline & \multicolumn{7}{|l|}{ ANOVA } \\
\hline & $\mathrm{F}$ & 8.78 & 90.145 & 93.735 & 51.60 & 379.775 & 23.22 \\
\hline & p-value & 0.007 & $<0.001$ & $<0.001$ & $<0.001$ & $<0.001$ & $<0.001$ \\
\hline \multirow[t]{7}{*}{$\mathrm{C}_{\text {Pbio }}$} & $\operatorname{CSR}^{\mathrm{a}}$ & $77.50 \pm 1.71$ & $229.74 \pm 1.30$ & $266.61 \pm 1.41$ & $442.90 \pm 32.30$ & $56.88 \pm 2.50$ & $88.06 \pm 3.09$ \\
\hline & SR170 ${ }^{b}$ & $70.86 \pm 6.08$ & $165.24 \pm 18.75$ & $274.50 \pm 33.04$ & $432.41 \pm 55.27$ & $79.59 \pm 1.78$ & $96.17 \pm 18.16$ \\
\hline & SR200 ${ }^{b}$ & $95.82 \pm 7.67$ & $187.84 \pm 13.94$ & $334.81 \pm 27.39$ & $533.73 \pm 25.41$ & $89.78 \pm 0.80$ & $86.53 \pm 7.99$ \\
\hline & SR280 ${ }^{b}$ & $102.44 \pm 10.55$ & $210.04 \pm 23.06$ & $384.53 \pm 34.30$ & $633.32 \pm 76.07$ & $108.92 \pm 1.35$ & $91.65 \pm 6.57$ \\
\hline & \multicolumn{7}{|l|}{ ANOVA } \\
\hline & $\mathrm{F}$ & 12.69 & 8.63 & 10.61 & 10.55 & 305.89 & 0.48 \\
\hline & p-value & 0.002 & 0.007 & 0.004 & 0.004 & $<0.001$ & 0.708 \\
\hline \multirow[t]{7}{*}{$\mathrm{C}_{\mathrm{Nbio}}$} & $\operatorname{CSR}^{\mathrm{a}}$ & $71.08 \pm 2.41$ & $384.44 \pm 0.48$ & $137.28 \pm 1.93$ & $321.11 \pm 10.17$ & $4.58 \pm 1.82$ & $29.05 \pm 0.33$ \\
\hline & SR170 ${ }^{b}$ & $92.98 \pm 6.44$ & $507.41 \pm 21.11$ & $188.90 \pm 31.92$ & $381.67 \pm 26.01$ & $7.04 \pm 1.85$ & $43.04 \pm 9.52$ \\
\hline & SR200 ${ }^{b}$ & $81.80 \pm 7.91$ & $539.38 \pm 13.39$ & $177.22 \pm 27.86$ & $377.82 \pm 59.45$ & $2.05 \pm 0.27$ & $65.78 \pm 8.60$ \\
\hline & SR280 ${ }^{b}$ & $116.67 \pm 10.65$ & $705.93 \pm 23.70$ & $244.46 \pm 33.36$ & $487.93 \pm 116.47$ & $5.22 \pm 0.41$ & $90.26 \pm 5.95$ \\
\hline & \multicolumn{7}{|l|}{ ANOVA } \\
\hline & $\mathrm{F}$ & 20.48 & 177.51 & 6.2 & 4.48 & 7.34 & 17.25 \\
\hline & p-value & $<0.001$ & $<0.001$ & 0.018 & 0.04 & 0.011 & $<0.001$ \\
\hline
\end{tabular}

${ }^{\mathrm{a}}$ CSR-Solid residue in control experiment. ${ }^{\mathrm{b}}$ SR170, SR200, and SR280 denote the solid residue conditions after SCWT treatment under 170,200 , and $280{ }^{\circ} \mathrm{C}$, respectively. 
Table 4. Concentrations of heavy metals released in TCLP tests (unit: $\mathrm{mg} \mathrm{kg}^{-1}$ ).

\begin{tabular}{cccccc}
\hline HMs & CSR $^{\mathrm{a}}$ & SR170 $^{\mathrm{b}}$ & SR200 $^{\mathrm{b}}$ & SR280 $^{\mathrm{b}}$ & Permissible limits $^{c}$ \\
\hline $\mathrm{Cr}$ & $0.300 \pm 0.061$ & $0.141 \pm 0.006$ & $0.424 \pm 0.053$ & $0.079 \pm 0.018$ & 5.0 \\
$\mathrm{Ni}$ & $11.751 \pm 1.62$ & $3.881 \pm 0.357$ & $12.165 \pm 1.596$ & $3.298 \pm 0.672$ & 5.0 \\
$\mathrm{Cu}$ & $5.047 \pm 0.709$ & $0.600 \pm 0.035$ & $1.387 \pm 0.393$ & $0.128 \pm 0.042$ & Not enlisted \\
$\mathrm{Zn}$ & $2.251 \pm 0.432$ & $0.391 \pm 0.047$ & $1.429 \pm 0.297$ & $0.312 \pm 0.049$ & 5.0 \\
$\mathrm{Cd}$ & $0.722 \pm 0.092$ & $0.070 \pm 0.001$ & $0.171 \pm 0.050$ & $0.044 \pm 0.011$ & 1.0 \\
$\mathrm{~Pb}$ & $0.028 \pm 0.001$ & $0.045 \pm 0.002$ & $0.081 \pm 0.005$ & $0.025 \pm 0.002$ & 5.0 \\
\hline
\end{tabular}

${ }^{\mathrm{a}} \mathrm{CSR}$-Solid residue in control experiment.

${ }^{\mathrm{b}}$ SR170, SR200, and SR280 denote the solid residue conditions after SCWT treatment under 170, 200, and $280{ }^{\circ} \mathrm{C}$, respectively.

${ }^{\mathrm{c}}$ USEPA, Test Methods for Evaluating Solid Waste, Physical/Chemical Methods (SW-846). 


\section{Figure captions}

Fig. 1. The total contents of heavy metals in liquid phase before and after SCWT treatment. LS-liquid sample after vacuum filtration, LS170, LS200, and LS280 denote the total amount of specific heavy metal in the liquid phase after SCWT treatment under 170,200 , and $280^{\circ} \mathrm{C}$, respectively.

Fig. 2. The total contents of heavy metals in solid residue before and after SCWT treatment. CSR- solid residue in control experiment (without SCWT treatment), SRsolid residue. SR170, SR200, and SR280 indicate the total amount of specific heavy metal in the solid residue after SCWT treatment under 170,200 , and $280^{\circ} \mathrm{C}$, respectively.

Fig. 3. Fractional distribution changes of each metal in sewage sludge before and after SCWT treatment. CSR-solid residue in control experiment (without SCWT treatment), SR-solid residue. SR170, SR200, and SR280 indicate the change of corresponding heavy metal fraction in the solid residue after SCWT treatment under 170, 200, and $280^{\circ} \mathrm{C}$, respectively.

Fig. 4. Leaching rate of heavy metals in TCLP tests. CSR- solid residue in control experiment (without SCWT treatment), SR-solid residue. SR170, SR200, and SR280 indicate the leachability change of heavy metals in the solid residue after SCWT treatment under 170,200 , and $280^{\circ} \mathrm{C}$, respectively. 


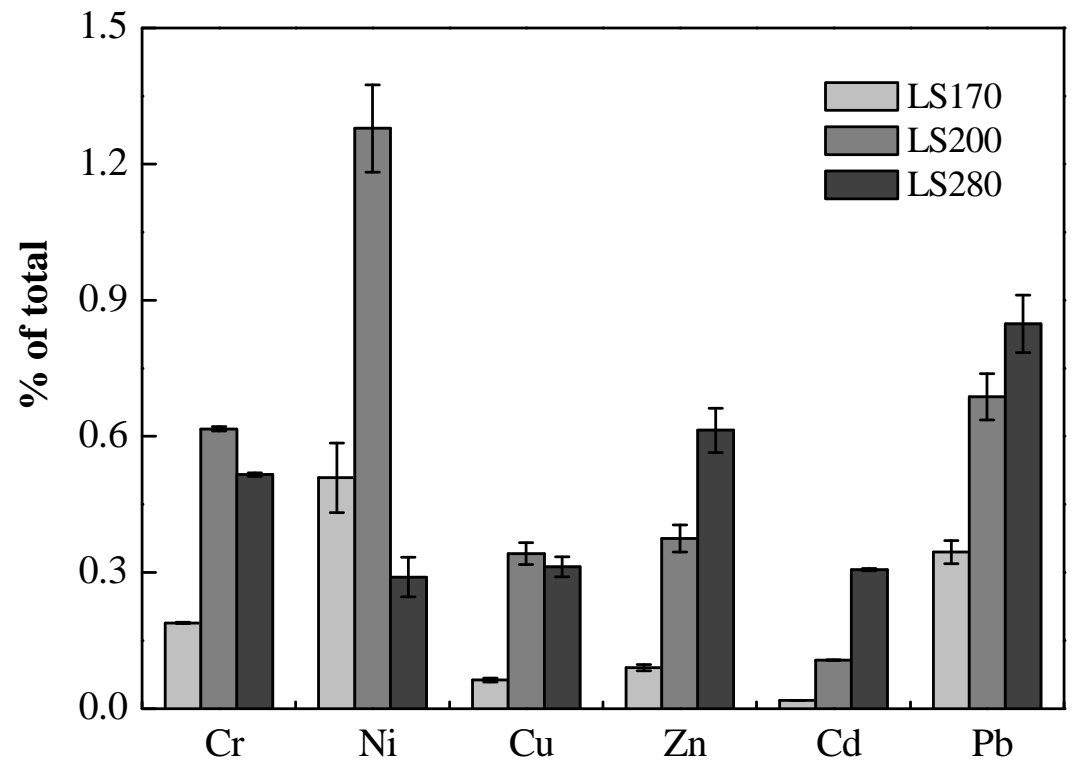

Fig. 1 Shi et al. 


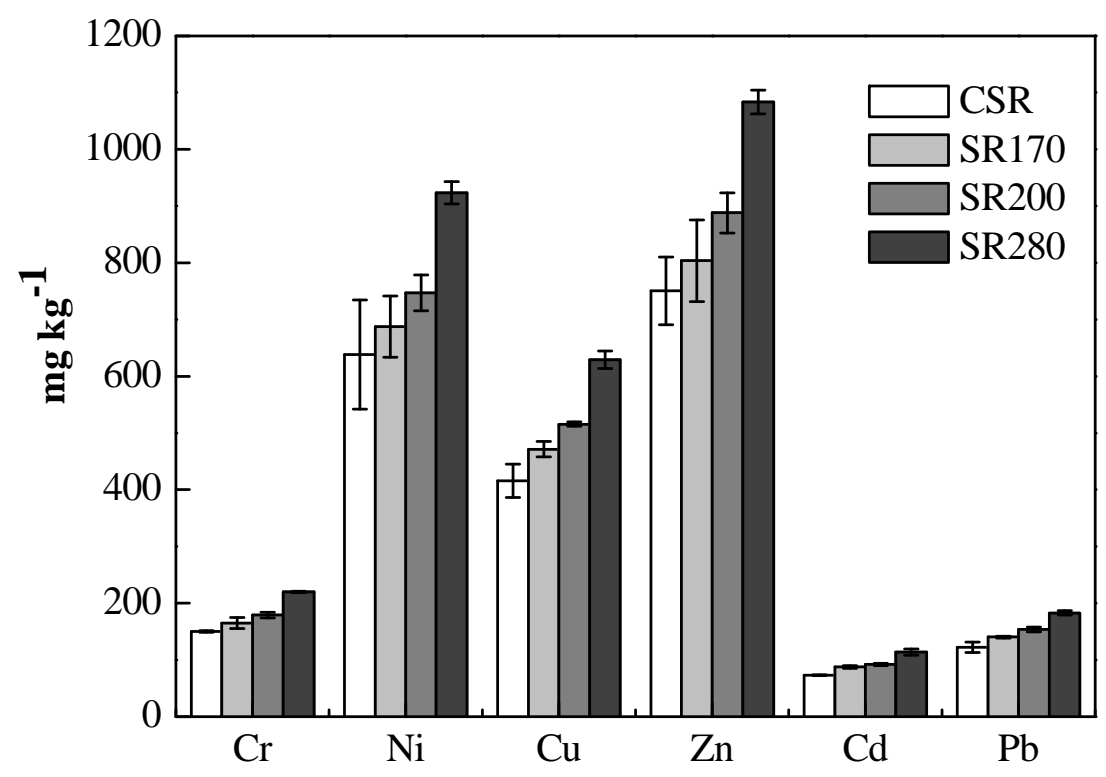

Fig. 2 Shi et al. 

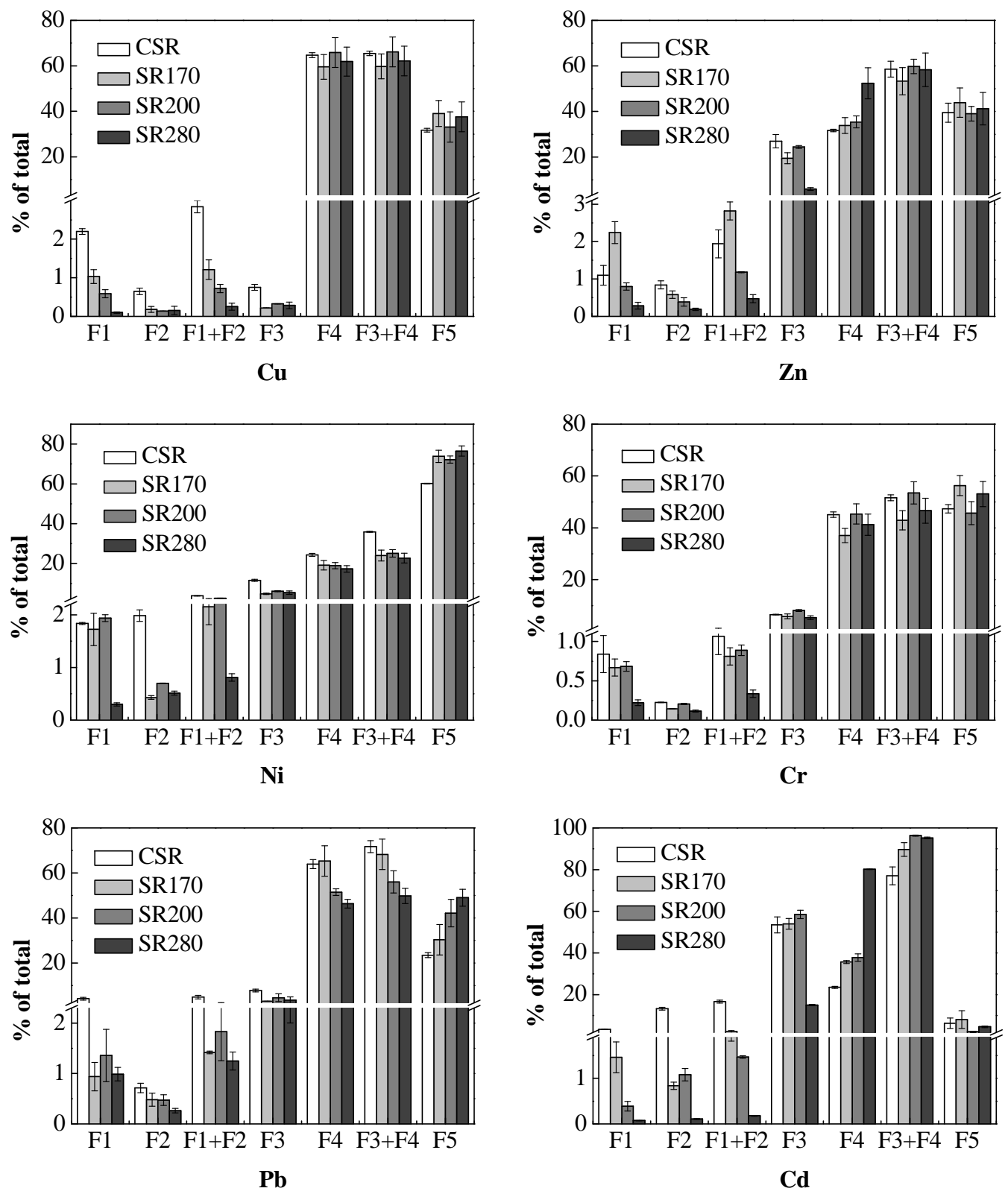

Fig. 3 Shi et al. 


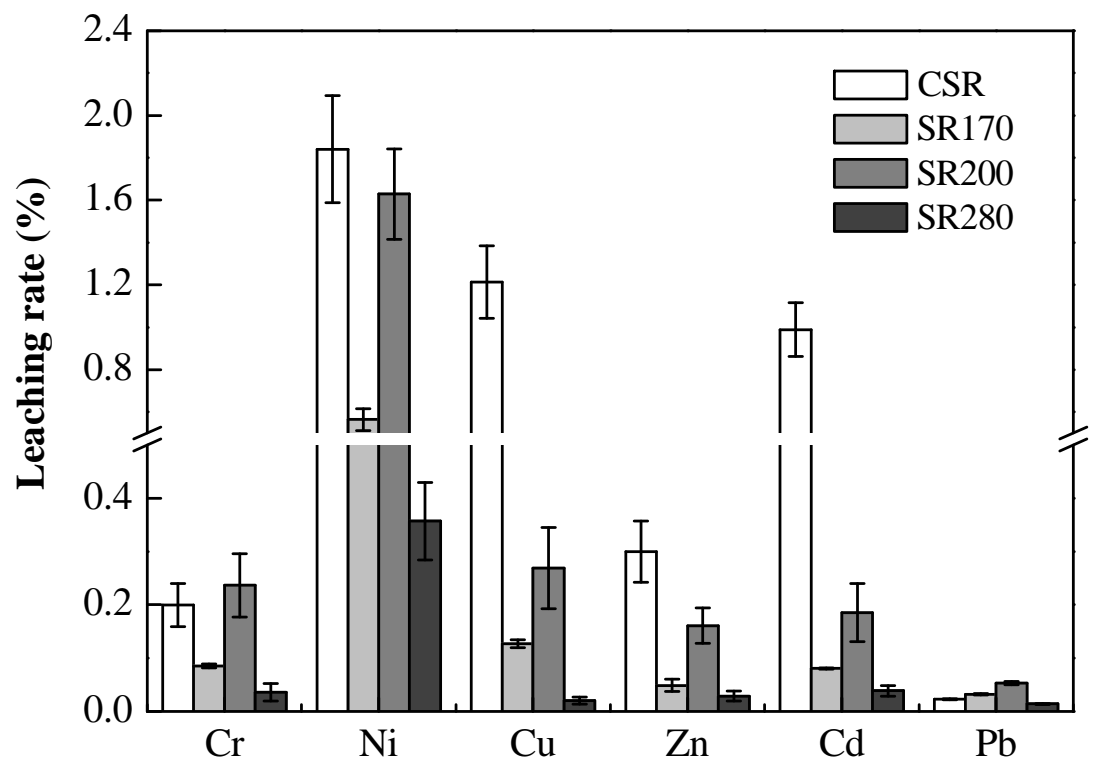

Fig. 4 Shi et al. 